\title{
Research on Countermeasures to Develop Group-based Education for Mechanical Majors in Higher Vocational Colleges
}

\author{
Zhang Rong \\ Department of Mechanical Engineering, Dalian Vocational \& Technical College, Dalian, Liaoning, \\ 116037 ,China \\ Lzhch11993@sina.com
}

Keywords: Higher vocational colleges; Group-based education; Mechanics; Countermeasure research

\begin{abstract}
This paper focuses on group-based higher vocational education in theoretical basis, training validation and development direction, hoping to promote its development. Based on an analysis of the definition and application of group-based higher vocational education, this paper then researches from vocational education, teaching management and social service, working out the basic principles that should be abided by in running group-based higher vocational education and summarizing the theory, organization structure and management mechanism of its development. The ultimate aim is to form a complete set of systematical, applicable and feasible theoretical system for group-based higher vocational education.
\end{abstract}

\section{Introduction}

In our educational system accounted for half of higher vocational education has become an important part of national economy and social development. And constantly promote the necessary steps to scale development of higher vocational education is also technology and education policy.

At present, combined with the further development of the national economy, with the deepening of the international standards, the improvement of vocational education theory and the organic combination of advanced teaching mode. Teaching concepts can be drawn lessons from abroad and the development of a new generation of educational technology, have decided the high-skilled talents training target. Our country need a lot of business, technology exquisite quality, can be competent the job of practical production line operation. Create favorable condition for the development of the above aspects of higher occupation education, the higher occupation education is not only to cultivate high skilled talents to the economic and social development and construction, is also the important measures to increase business, employment and re-employment.

However, combined with the development of higher vocational education in our country now, the actual requirements of the graduate school students and all sectors of society have a certain distance. Only optimize the market, aimed at industry development, to meet the needs of enterprises, to make the higher vocational education to serve economic development better.

\section{Vocational Education Group Connotation and Research}

The so-called Group of Vocational Education, in fact, for the professional integration of resources, so as to optimize resources, reduce the maximum possible cost of teaching, improve teaching effectiveness. The way of group education is the reform and innovation of teaching model and management mode of higher vocational education. It is also an important way of development of vocational education. With the deepening and development of vocational education, the idea and mode of group education is more urgent, which is also a way to improve the quality of vocational education and talent level of teaching methods. The development of Higher Professional Education we should do ideological emancipation, further change educational philosophy and ideas, continue to adhere to serve the community as a direction to cultivate students' ability as the core, the student, to meet market demand, cultivate sustainable development and innovation ability for regional economic development requires highly skilled personnel applications. Vocational colleges should 
continue to explore the teaching mode, the implementation of a combination of engineering, strengthening the development of school-enterprise cooperation and innovation management mechanism, as well as to introduce new models of school group. Many domestic scholars learn from foreign advanced concepts for professional nature and structure of the educational aspects of the research group , combined with experience in education, vocational education, some domestic groups of vocational education group also carried out some theoretical studies.

Research on Higher Education Group Properties, Types and Structures. There are three kinds of organizing mode of higher vocational education group, which is the restructuring, contract type, and mixed type. By studying the structure and properties of higher vocational education collectivization, you can see the advantage of higher vocational education collectivization and meaning. Its value is immeasurable. However, further analysis of the various pattern and features of the higher vocational education collectivization, can be found in the formation of reason has not been studied, thus all kinds of higher vocational education collectivization of the current domestic existing lack of theoretical analysis and research. Combined with the relevant contents of the company law to analyze, group education institutions with the company's similar, the recombinant, compact also exist in teaching mode and hybrid several, many scholars have defined the types of all kinds of higher vocational education collectivization, but with practice the analysis of the very few. In this paper, combined with examples of school group to study collectivization school-running, hope to collectivize school-running promote research results, in addition, for the characteristics of various construction modes of higher vocational education collectivization should also further study, for the vocational education group in a proper choice of the mode of forming.

Study Group of School Development of Higher Vocational Education. Through the Vocational Education Group of the feasibility of the theoretical analysis can be seen, there Higher Education Group's organizational structure in line with modern trends, optimize the benefits of vocational education resources, the formation of intensive development advantages. Vocational Education Group can be achieved by a combination of internal resources and distribution of the Group optimized to obtain larger economic benefit, to save running costs through common unified procurement and distribution, can also take reasonable specialization, centralized management, reduce occupational Education management costs and continuously improve the educational level and quality of education. Vocational Education Group is an organization that is open and can be regular exchange with the outside environment, resources, information, energy and other aspects of the integrity of the occurrence of a desired function $1+1>2$.

\section{Higher Education Group in Problems}

How to Promote Industries and Enterprises to Participate in the Higher Education Group. To get enterprises to actively participate in the Higher Education Group in the past, we should let the relevant business interests in Higher Education Group implemented only enable enterprises to obtain the relevant profit educational group, which is to achieve vocational education Group of school of the key.

How Higher Education Group Let Go a Sustainable Path. Coordination within the group related to the interests of the Group and stronger, and then absorb the outstanding resources outside the group, so that vocational Education Group into a virtuous cycle is the key. Vocational Education Group in the course of the operation, some of Running Vocational Education Group developed very well, but there are also some less than satisfactory, through the analysis can be found, the key issue is the division of responsibilities among the various entities within the group range of each other and distribution of benefits between the ability to handle. For the Group to achieve sustainable development, rely on the group's own capacity is still very limited, if group can attract targeted government preferential policies to support investment and school conditions, it will be possible to guide the institutions join the Group of School team, promote enterprise and development of the industry to join the group to provide school teaching cycle develop reliable power.

Take What Effective Management System and Operation Mechanism. Through the main body of China's Higher Education Group structure and operating characteristics for analysis, it can 
be found that the current Higher Education Group can be divided into vocational education group industry type, regional-based vocational education group and composite Vocational Education Group. Higher Vocational Education Group mode to the comprehensive reform of the school gradually started. What management system and operation mechanism to take a direct impact on the success or failure of the Vocational Education Group. This is also one of the issues addressed in this pre- study.

\section{Countermeasures of Vocational Education Group Development-A Case Study of Mechanical Specialty}

At present, China's higher vocational institutions accounted for half of the national university, and how to strengthen the construction of vocational education is very important. In the process of building "demonstration school", "the backbone of the school", many schools have in promoting school and enterprise, work and study, but the results are unsatisfactory. Because most of the school and enterprise is by personal feelings, the relationship between the leadership of "bound" together. There is no effective mechanism to bind, to focus only on short-term benefits, not focused on building long-term mechanism, this result is the "The tea cools down as soon as the person is gone", for leadership, for a contact person, the school-enterprise cooperation will be difficult to sustain longer. So how would such a school-enterprise cooperation benefits continue, it is worth considering.

Higher Education Group-running down the Road, so the Innovation System and Mode of Higher Vocational Education. In November 2012 set up a Vocational and Technical College of Dalian and the Dalian Municipal Light Industry School as the lead institutions of the Vocational Education Group Dalian Equipment Manufacturing (Vocational Education Group),the United Association of Machinery Industry in Dalian, Dalian Mould Association and 32 equipment Manufacturer company. Formed a professional manufacturing equipment Personnel Training as a fundamental task of sharing through government guidance, industry guidance, enterprises and institutional mechanisms for deeper cooperation between schools, school-enterprise resources to achieve within the group. Promote school -enterprise cooperation, cooperation in education, employment cooperation, cooperation and development. Through years of practice found that the school system to reduce the operating cost of vocational education, improve teaching efficiency and quality graduates for further education to vocational bigger, stronger provide an important driving force. In the past, an industry aligned with a professional, such as mold design and manufacturing expertise, the corresponding mold manufacturing, installation and commissioning of the refurbishment, a student can only accommodate one kind of job, major in vocational difficult convergence. This problem by Higher Education Group will gradually be resolved.

Higher Education Group Embodiment Mode, Focusing on Capacity-building, the Quality of Education in one, to Create Positive Conditions for the Development of the National Economy, Improve People's Cultural Quality. First of all, the students of higher vocational education will eventually go society, employment has become one of the students face the difficulty at present. On the one hand, the difficulty in employment. Migrant workers or college students face the social reality of "not enough", on the other hand, many enterprises to find the appropriate professional and technical personnel, leading to state the number of senior technical talent gap widening. Therefore, higher vocational schools to make students graduate employment smoothly, we must try to higher vocational education collectivization school-running ideas. Dalian vocational technology college will give full play to the advantages of "group", take advantage of the school construction of all kinds of machinery, through cooperation with enterprises. On current various kinds of machinery in the employment situation of the enterprise, professional research, the task of graduate student work, professional ability, professional ability to investigate to understand. At the same time find out the problems existing in the cooperation in running schools, to better the professional standards to provide the basis. Second, all kinds of professional similar through high school is also a factor in increasing employment pressure. To dalian vocational technology college in mechanical categories of numerical control technology professional, for example, almost all of 
school will open numerical control technology professional, this is also the result of the role of market economy. This can make a lot of school cultivated the students' knowledge structure and professional skills are highly similarity, also increased the employment pressure of the society. Dalian Vocational Technical College of Vocational Education Group in the thoughts of running for the Group's internal resources integration and separation adjustment decomposed into several dimensional numerical control technology professional technical expertise, professional research in different fields and coordination in order to achieve Differentiation. Through several years of practice has proved that do to a great extent, alleviate the employment pressure of the society. Again, the vocational education collectivization school-running ideas to optimize the group internal resources, as well as improve the efficiency greatly reduces the cost of running. Between different individuals within the group, on the basis of group interests maximize, resources integration and sharing. To save the group's cost and even social cost.

Implement the Optimal Combination of Teaching Resources between the Parties, Promoting the Construction of Higher Vocational Education Group. There are some links and differences between the scale and the level of teaching in higher vocational schools, which can be organically combined with each other, such as institutions, enterprises, vocational schools, private units and so on. To maximize the use of the group of school platform, the integration of resources and favorable conditions of the combination of various aspects of the optimization, to explore suitable development mode, so as to bring their own maximum benefit. The 2lst century is the century that our country will have to realize the modernization in an all-round, "to realize modernization, the key is in the science, the foundation is in the education". Higher vocational education plays an important role in the development of the education system and social development, and it is also the most important part of the social economic development. It is an important way for the development and promotion of higher vocational education to study and discuss the concept of enterprise management in the new economic form, discuss and study the mode of running a school.

\section{Conclusion}

The level of the group of higher vocational education has become an important symbol to measure the level of Vocational Education in a country. And to a great extent, it affects the quality of school teaching, the ability of running a school and the size of the school and the quality of graduates. Through the analysis of the connotation and mode of vocational education, this paper finds out the problems existing in it. Based on the experience and achievements of the group in Dalian Vocational and Technical College in the last few years, this paper summarizes and puts forward some suggestions for the higher vocational education group.

\section{Acknowledgment}

This work was supported by Dalian Vocational \& Technical College, we are indebted to the support and encouragements received from the staff and colleagues of the department of Mechanical Engineering. Fund Project: Dalian Institute of Vocational and Technical Education Sciences 2015 annual general topics, project number:DZKY2015B51

\section{References}

[1] Xianghong Liu, Duan Jun. Research and Exploration Group of School Reform in Higher Education[M]. China University Teaching, 2012(5).

[2] Guoqin Xu. Technical Preparedness Plans from the US Development of Vocational[J]. Education Development, 2002(2).

[3] Kuang Ying. Comparison of Higher Vocational Education. Development and Change[M]. Shanghai Education Press, 2006.10. 
[4] GAN Guang-sheng, ZHANG Jun-feng. Tentative Discussion about the Role of School-running Policy Guarantee in Vocational Education Group. Journal of Hefei Normal University, 2014(4).

[5] Xinping Liang. Thoughts on Establishing Higher Colleges Group-running Mechanism. VOCATIONAL \& TECHNICAL EDUCATION FORUM, 2011(4). 